\title{
Spatial sampling design for sediment quality assessment in estuaries
}

\author{
Sandra Caeiro ${ }^{\mathrm{a}, *}$, Marco Painho ${ }^{\mathrm{b}}$, Pierre Goovaerts ${ }^{\mathrm{c}}$, Helena Costa ${ }^{\mathrm{d}}$, Sandra Sousa ${ }^{\mathrm{b}}$ \\ a IMAR, Department of Exact and Technological Sciences, Portuguese Distance Learning University, R. Escola Politecnica, 147, \\ 1269-001 Lisbon, Portugal \\ ${ }^{\mathrm{b}}$ Institute for Statistics and Information Management of the New University of Lisbon, Portugal, Campus de Campolide, 1070-124 Lisbon, \\ Portugal \\ ${ }^{\mathrm{c}}$ Biomedware Inc., 516 North State Street, Ann Arbor, MI 48104, USA \\ ${ }^{\mathrm{a}}$ IMAR, Faculty of Science and Technology of the New University of Lisbon, Quinta da Torre - 2829-516 Caparica, Portugal
}

Received 28 July 2002; received in revised form 16 April 2003; accepted 20 April 2003

\begin{abstract}
Unusual difficulties are encountered when characterizing the spatial distribution of the properties that collectively define the state of estuaries. Due to the variability of these estuarine conditions, greater sampling efforts are often necessary to describe estuarine environments, as compared to other aquatic systems. That is why in coastal management studies, where the collection of data is sometimes very difficult and time-consuming, a robust sampling strategy is essential. The aim of this study is to design a spatial sampling strategy for estuarine sediments, using prior information on the spatial variation of sediment granulometry. Systematic unaligned sampling with a grid cell size of $750 \times 500 \mathrm{~m}$ was chosen on the basis of semi-variogram analysis, and was shown to have distinct advantages. This design was sampled for sediment parameters using a GPS-receiver and mapped within the digitized shoreline of the estuary. The estuary shoreline was digitized on the basis of aerial ortho-photography with tidal ebb determination. The sampling is intended to define the boundaries of environmental management areas for the Sado Estuary, situated on the west coast of Portugal. The research represents one of the initial phases in the development of a Sado Estuary environmental management system integrated into a Geographic Information System.
\end{abstract}

C) 2003 Elsevier Ltd. All rights reserved.

Keywords: Geographic Information System; Sampling design; Estuaries; Arcview software; Semi-variograms; Aerial photo digitalization

\section{Introduction}

In estuaries large-scale patterns of spatial variability include the longitudinal salinity gradient along the continuum between the estuarine drainage basin and the coastal ocean. Sources of small-scale spatial variability, unique to or amplified for estuaries, overlap this trend. These sources of small-scale spatial change include distributed point sources, such as human waste discharges; features of water circulation, such as fronts or convergences that create high local turbidity; or patchiness

${ }^{*}$ Corresponding author. Tel.: +351-21-391-6340; fax: +351-21396-9293.

E-mail addresses: scaeiro@univ-ab.pt (S. Caeiro); painho@isegi.unl.pt (M. Painho); goovaert@engin.umich.edu (P. Goovaerts); mhcosta@mail.fct.unl.pt (H. Costa); ssousa@isegi.unl.pt (S. Sousa). resulting from irregularities in bottom topography (Jassby et al., 1997). Due to the variability of these estuarine conditions, greater sampling efforts are often necessary to describe estuarine environments, compared to other aquatic systems. That is why in coastal management studies, where the collection of data is sometimes very difficult and time-consuming, it is a prerequisite to design sampling strategies that detect the existing spatial heterogeneities (Kitsiou et al., 2001). Sample size and design is also very important when the objective is to interpolate and create contour maps for a variable within a region (Haining, 1990).

Using a Global Positioning System (GPS)-receiver for field sampling allows inclusion in a Geographic Information System (GIS) for subsequent analytical, statistical and modelling analysis. The use of GIS technology for coastal management provides: (i) great visualization 
improvements of such data for space-use management; (ii) enhanced use of remotely sensed data; (iii) high quality graphical output for the dissemination of information; (iv) development of efficient data and information management infrastructures (Ricketts, 1992) and (v) a combination of dissimilar data, such as socio-political boundaries, bottom types and habitat distributions (Stanbury and Starr, 1999). Remote sensing has shown itself to be cost-effective for mapping shoreline habitats when compared with land-based surveys (Mumby et al., 1999). In particular, aerial photography has been used in a wide range of coastal applications. Its most extensive use has been for determining shoreline boundary variations. The integration of analytical GIS, GPS and remote sensing is an effective planning tool and a sound basis for continued coastal monitoring (O'Regan, 1996).

The aim of this study is to design a spatial sampling strategy for estuarine sediments, using prior information on the spatial variation. The design covers the smallscale variability and the uniformity of the study area. The sampling design strategy will be applied within an estuary boundary digitized from aerial ortho-photography. This sampling strategy is for the future definition of environmentally homogeneous sediment areas for the Sado Estuary, on the west coast of Portugal. This research represents one of the initial phases in the development of an environmental management system for the Sado Estuary, integrated into a GIS.

\section{Spatial sampling designs}

The selection of a sample size and design, an estimator for the population characteristics and sampling variance are fundamental requirements for sampling experiments. The presence of spatial dependency has implications for all these stages (Haining, 1990).

Also studied in the literature are the three main forms of point sampling in a geographic region: simple random sampling, stratified sampling and systematic sampling. Spatial variables are almost always auto-correlated according to some scale, and in these circumstances simple random sampling is inefficient in the sense that it requires more effort to achieve a given precision than any other scheme. Stratified sampling is more precise than simple random sampling. In general, the smaller the cells, the smaller the within-stratum variance. Systematic sampling provides the most precise estimates for a given sampling effort (Cochran, 1977; Clark and Hosking, 1986; Haining, 1990; Thompson, 1992; Jassby et al., 1997; Webster, 1999).

For the local estimation of spatial variables, a regular grid is the most appropriate design (Flatman et al., 1987; Haining, 1990). Unfortunately, systematic sampling does not provide an entirely satisfactory assessment of the estimation variance because the sampling points are not randomized once the grid has been placed on the land. A potential hazard of systematic sampling is bias arising if a sampling grid is offset to one side or another of a region in which there is a trend in the variable of interest (Webster, 1999). In estuarine environments the abiotic and biotic variables are usually strongly dependent and vary according to the physical regimes of the estuaries, evaluated through the three main process agents: waves, tides and wind. One solution is to design a systematic unaligned sampling suggested by Berry and Baker (1968). The bias is reduced and the resulting design has greater precision than any of the other methods mentioned (Cochran, 1977). This approach avoids the periodicities of the systematic approach, gives good coverage over an area, is efficient, and deals with most distributions (Clark and Hosking, 1986).

The environmental monitoring and assessment program (EMAP) of the United States Environmental Protection Agency uses systematic sampling in aerial coverage yet probabilistic sampling for its design (Overton et al., 1990). In Delaware and Maryland Coastal Bays, an appropriate number of EMAP grid cells is selected randomly for each subsystem of coastal bays and a random site from within these cells is selected (Chaillou et al., 1996).

\subsection{Geostatistical approach for spatial sampling designs}

A robust spatial sampling design applied to estuarine environments requires prior information on the spatial correlation in the estuary, which can be quantified using semi-variogram analysis (Burgess and Webster, 1984; Flatman et al., 1987; Jassby et al., 1997; Van Groenigen et al., 1999; Van Groenigen et al., 2000; Kitsiou et al., 2001). Although highly successful in other areas, for example soils, few studies apart from Reed et al. (2000) have been conducted in estuarine environments using this kind of approach. The use of previous samples to direct additional sampling is important for the minimum kriging variance of regional variables (Van Groenigen et al., 1999).

The semi-variogram $\hat{\gamma}(h)$ measures the dissimilarity between values of the regionalized variable $z,\left\{z\left(u_{\alpha}\right)\right.$, $\alpha=1, \ldots, n\}$, with respect to the spatial separation $h$ (Goovaerts, 1997):

$\hat{\gamma}(h)=\frac{1}{2 N(h)} \sum_{\alpha=1}^{N(h)}\left[z\left(u_{\alpha}\right)-z\left(u_{\alpha}+h\right)\right]^{2}$

where $N(h)$ is the number of pairs of data locations a vector $h$ apart. A model of spatial variability assumed to be characteristic of the sampled data is fitted to the experimental semi-variogram (Fig. 1). The semi-variogram reaches a plateau, $C$, at the range of correlation $(a)$ since data separated by a larger distance are considered 


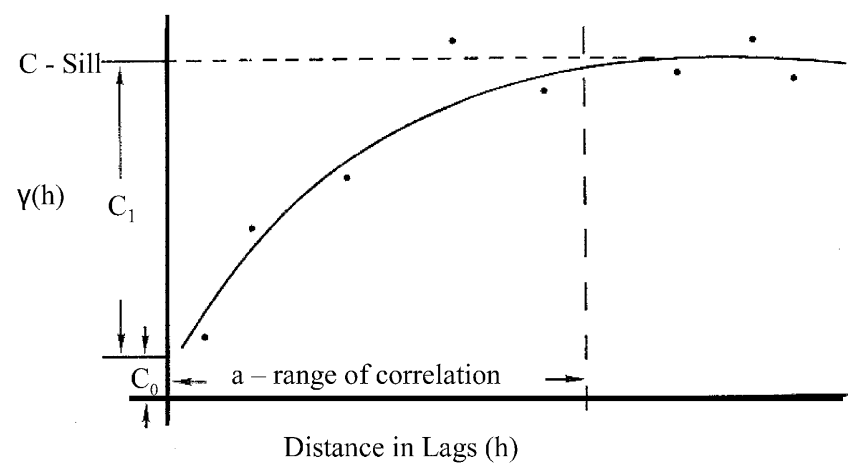

Fig. 1. A typical semi-variogram and fitted model (adapted from Flatman et al., 1987).

spatially independent. This distance is important for the sampling plan in that to collect non-redundant observations they must be at least the range of correlation apart. $C_{0}$ combines random variance factors, such as sampling and analytical error, along with any spatial variability that may exist at a distance smaller than the shortest sampling interval (Flatman et al., 1987).

As already stressed, in estuarine environments the spatial variability is usually direction-dependent. Such spatial anisotropy is better identified when the experimental semi-variogram values are plotted in the system of coordinates $\left(h_{x}, h_{y}\right)$, yielding the semi-variogram map (Goovaerts, 1997).

\section{Study area}

The Sado Estuary is the second largest estuary in Portugal, with an area of approximately 24,000 ha. It is located on the west coast of Portugal, $45 \mathrm{~km}$ south of Lisbon, within a boundary box of $8^{\circ} 42^{\prime} \mathrm{W} 38^{\circ} 25^{\prime} \mathrm{N}$ and $8^{\circ} 57^{\prime} \mathrm{W} 38^{\circ} 32^{\prime} \mathrm{N}$. Most of the estuary is classified as a nature reserve. Exception is made for the city of Setúbal, its port, and a considerable part of its surrounding area. The Sado Estuary basin is subject to intensive land use practices and plays an important role in the local and national economy (Caeiro et al., 2002). The difficulties of the reserve authorities in managing urban growth and industrial pressures are also reflected in the higher urban growth rate inside the protected area boundary, when compared with its surroundings (Painho et al., 1996). This is probably due to the fact that numerous official bodies are responsible for land use planning in the reserve area, causing, at times, management bottlenecks.

\section{Methods}

\subsection{Coastal boundary digitization}

Sado estuary coastal boundaries were digitized on the basis of aerial ortho-photos of 1:40,000, $1 \mathrm{~m}$ resolution
(CNIG, 1995) using ArcView 3.2® (Image Analysis $\left.{ }^{\circledR}\right)$ extension.

The estuary boundary was digitized using manual image classification (Robinson et al., 1995). This feature extraction approach is a combination of manual interpretation and digital image display. Using the mouse, the polygon of the interpreted features was traced from the image displayed on the colour monitor. Polygons are drawn on the image as they are digitized and are also stored as a shapefile and included in a GIS database. This method is less time-consuming than digital image classification. The latter method uses image processing to classify each pixel, based on the reflectance value in each spectral band. Considering our objective, digital image classification produces complex polygons with delineation problems that are difficult to manage, require generalization and manual editing to remove errors (Fig. 2).

Sandbanks did not appear in aerial ortho-photo maps, due to the height of the tide at the time the photos were taken. These morphologic structures suffer small changes in shape and location throughout time. However, their continuous presence in the estuary has been observed in recent decades. These structures were digitized using a 1:25,000 nautical chart (UKHO, 1999).
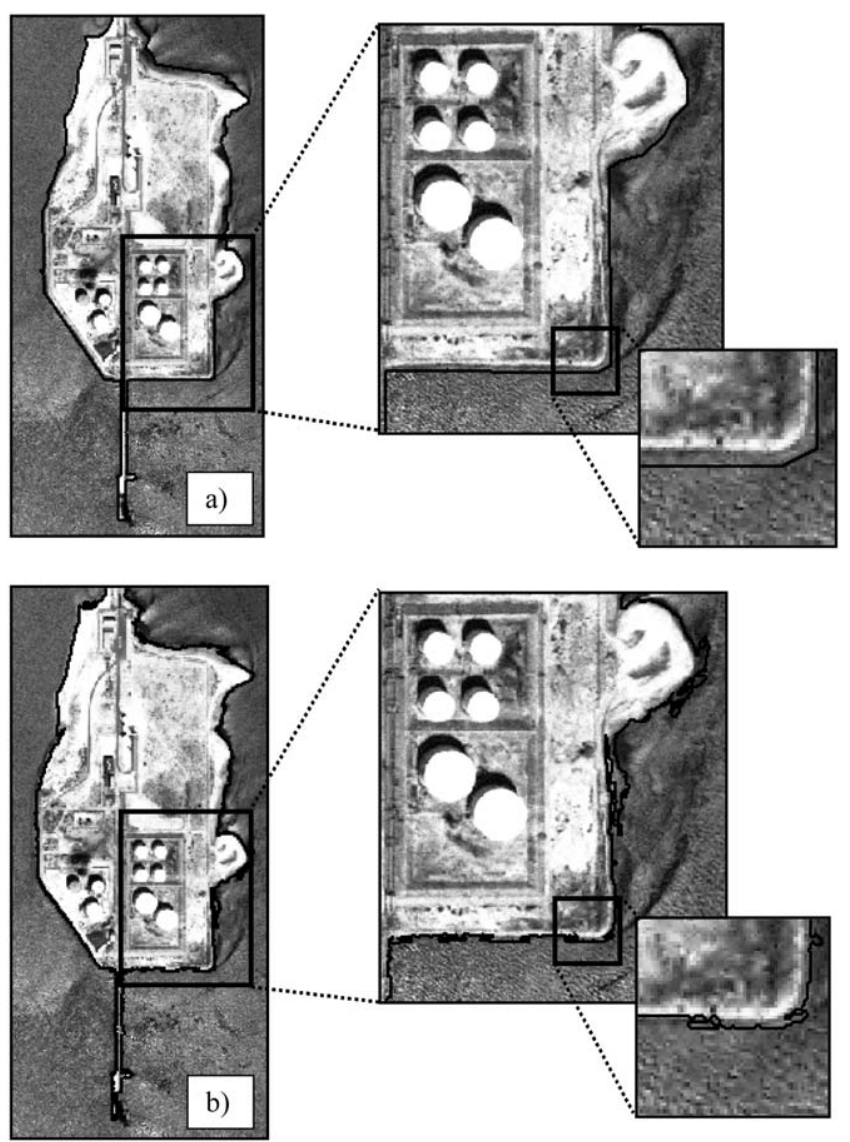

Fig. 2. Comparison between (a) manual image classification and (b) digital image classification. 
The digital estuary boundary was mapped in the transverse Mercator projection, in Lisbon datum.

Since aerial photos were taken at different stages of the tide, digitized boundary gauging was needed. The height of the tide was calculated for each aerial photo, using the date and time of each photo and the tidal data for three local harbours (IH, 1995) (Fig. 3). The height of the tide at any time after low tide was calculated with reference to an harmonic analysis of the marigraphic observation series of variable duration (IH, 1995):

$y_{1}=\frac{h+H_{1}}{2}+\frac{h-H_{1}}{2} \cos \left(\frac{\pi t_{1}}{T_{1}}\right)$

where $T_{1}$ is the time lag between low tide and high tide (min) for each photo, $t_{1}$ the time lag between low tide and the desired height of the tide (min), $H_{1}$ and $h$, respectively, the height of the high and low tides that demarcate the desired time lag, in relation to mean sea level (m).

The Thiessen method was applied to ascertain which ortho-photos were influenced by each piece of harbour tidal height data $\left(H_{1}\right.$ and $\left.h\right)$. Thiessen polygons, also referred to as the Dirichlet Tessellation or the Voronoi Diagram, define the individual 'regions of influence' around each of a set of points (Chrisman, 1997). This method does not take into account the estuary hydrodynamics, shape and channels. Since our study area was conducted in the estuary bay and not in highly convoluted short channels, this method provides a good estimation for linearly counted points.

\subsection{Sampling design}

A systematic unaligned design was chosen for sampling sediment characterization indicators to delineate environmentally homogeneous areas in the Sado Estuary. Although systematic sampling is more suitable for interpolation, using random samples in each grid provides some clustered locations that can be very helpful to infer the semi-variograms at small lags.

Grid unit length was assessed through analysis of experimental semi-variograms estimated using observations of a previous study (Rodrigues and Quintino, 1993). This work analysed sediment granulometry, a parameter strongly correlated with the sedimentary environment, at 133 sampling sites not regularly distributed along the estuary bay.

According to Flatman et al. (1987), the distance between sample locations should be half the correlation range of experimental semi-variograms $(a / 2)$ of previous data, in the case of a small nugget effect. In the case of a large nugget effect, sample distance should be less than two-thirds of the range of correlation $(2 a / 3)$. The grid should be laid out with no vertices unsampled. Semivariograms were computed and modelled using the public-domain software Variowin 2.2.

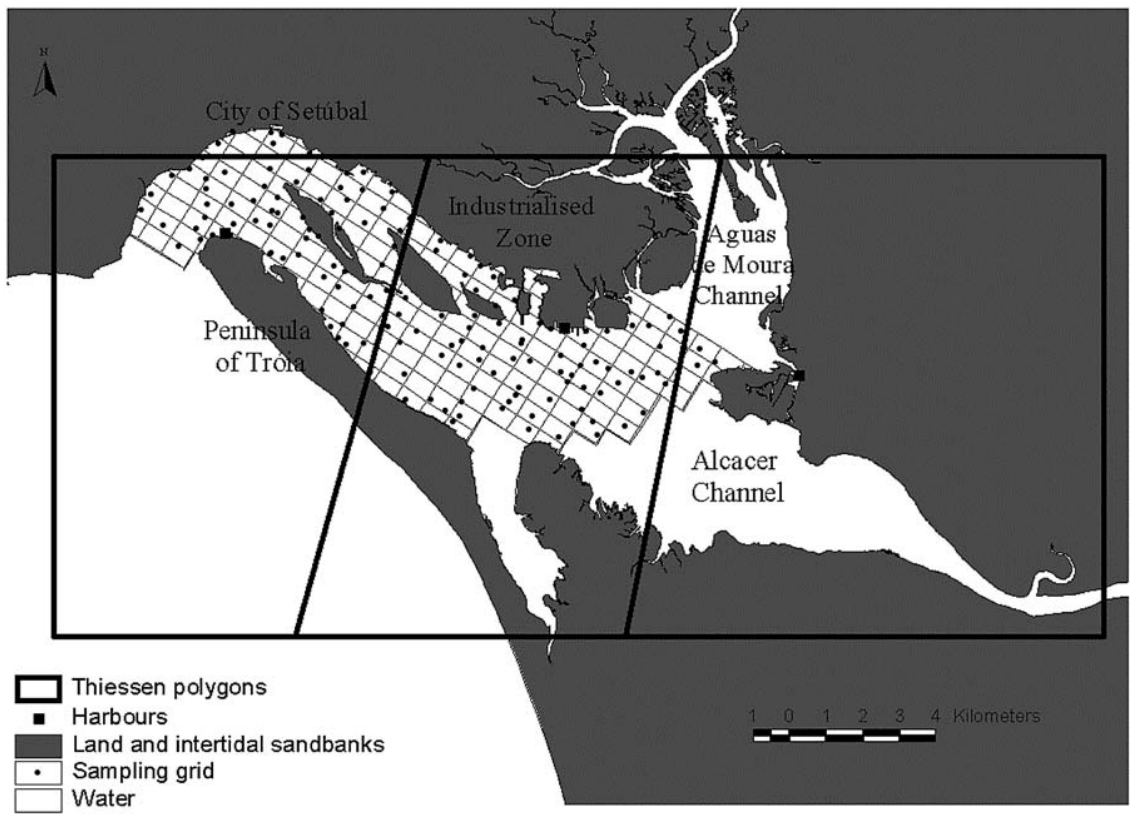

Fig. 3. Sado Estuary sediment sampling design within digitized boundary of the estuary. 


\section{Results and discussion}

\subsection{Coastal boundary digitization}

The digitized boundary of the estuary is shown in Fig. 3. The computed average tide height difference between low tide and the tide at the time when the photos were taken was $2.52 \pm 0.099 \mathrm{~m}$, corresponding to $4 \mathrm{~h} 19 \pm$ $16 \mathrm{~min}$, after the low spring tide. These tidal height differences are not relevant to our study area, because most of the shoreline is man-made with a steep slope, and thus a small ebb area. The maximum difference between the height of the tide in the aerial photos (only $0.3 \mathrm{~m}$ ) was minimized by choosing the lowest water level between two adjacent aerial photos for digitizing.

Despite the aforementioned limitations, this estuary boundary shows a satisfactory level of accuracy and validity when compared to other work, which has been carried out with other scales and sources of information (e.g. CNIG, 1990; Painho et al., 1996; UKHO, 1999; Martins et al., 2001). It is also the only known attempt to document an estuary line for this area. For the Troia Peninsula area (south of the estuary), Gomes et al. (2001) carried out a shoreline evolution study from 1948 to 1997 , using digitized photos and/on a scale of 1:40,000-1:2000, though without taking into account tidal ebb variations.

\subsection{Sampling strategy}

The semi-variogram map (Fig. 4) of fine fraction particles shows a clear anisotropy, with the maximum continuity observed in the direction of azimuth $120^{\circ}$. This is due to the fact that the variability in the estuary bay is greatest in the direction perpendicular to the water flow, which is consistent with other studies (Martins et al., 2001).

In the case of anisotropy a good strategy is to elongate the grid in the direction of the strongest correlation (maximum continuity) (Haining, 1990).

Few studies have computed semi-variograms for estuarine sediment parameters like fine fraction contents. Reed et al. (2000) computed omnidirectional semi-vari-

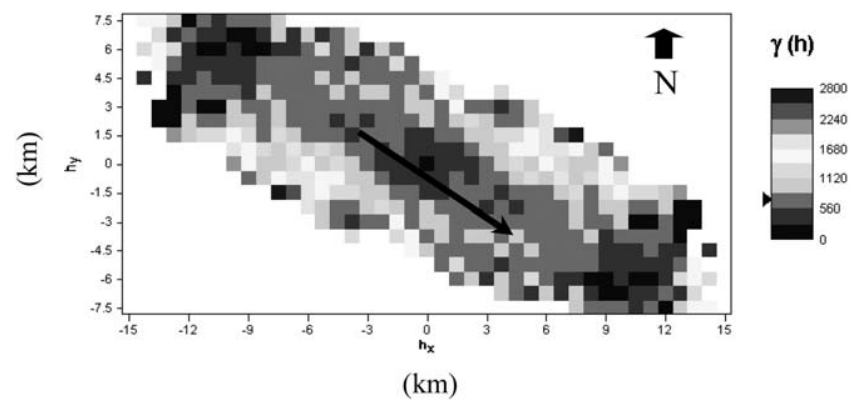

Fig. 4. Semi-variogram map for fine fraction contents to detect anisotropy. ograms for a particular sediment size of $<63 \mu \mathrm{m}$ in a UK commercial dock and obtained a large nugget variance, with little spatial dependence. This latter fact shows anisotropy of the variability of fine fraction values. Without the comparison of semi-variograms in at least two directions (major and minor spatial continuity) or ancillary information, like hydrodynamics, it is difficult to detect anisotropy and draw conclusions on spatial variability.

Semi-variograms were computed up to a distance of $5 \mathrm{~km}$ in the directions of azimuth $30^{\circ}$ and $120^{\circ}$ (see Fig. 5). Lag distances of $0.25 \mathrm{~km}$ and angular tolerances of $30^{\circ}$ were chosen, since they yielded the most easily interpretable semi-variograms. A spherical model with a range of $1.5 \mathrm{~km}$ in the direction of azimuth $120^{\circ}$ and 1 $\mathrm{km}$ in the perpendicular direction was fitted. As a result, Fig. 3 depicts the final grid cell definition, extending 750 $\mathrm{m}$ in the direction of maximum continuity and $500 \mathrm{~m}$ in the perpendicular direction $(a / 2)$.

This design has already been successfully used for sediment parameter sampling. The final grid included 153 sites covering the estuary bay as far as the entry of the Aguas de Moura and Alcacer Channels (Fig. 3) (sampling density of 153/57 $\mathrm{km}^{2}$ ). The random sampling point in each grid was attained every time the boat moved and reached a grid rectangle, using a GPSreceiver (Garmin GPS $12 \times \mathrm{L}$ ). This sampling was used for the further mapping of environmentally homogeneous sediment areas of the Sado Estuary applying geostatistical (i.e. kriging) interpolation techniques. Computed semi-variograms of the fine fraction collected in this sampling campaign (Caeiro et al., 2003) confirmed the spatial variability previously calculated.

Most studies of sampling design for estuarine sediment quality are conducted without a statistical basis. The choice of sampling points is mainly based on local characteristics, like sources of pollution. It is only for national or regional estuarine monitoring programs with a reduced and representative number of samples that more careful statistical support is used (e.g. Overton et al., 1990). Few studies have developed sampling strategy designs for the spatial assessment of coastal sediment quality (Table 1). The four studies listed in Table 1 show substantial differences in density (from 0.018 to 135 locations per $\mathrm{km}^{2}$ ) and spatial configuration of sampling points. These differences could be due to the spatial variability of sediment parameters in each coastal zone, in particular with the differences in geomorphological, biological and human pressures. These illustrate the importance of taking into account information from previous studies.

\section{Conclusions}

Statistical support including previous knowledge of spatial variability for sampling design definition is an 

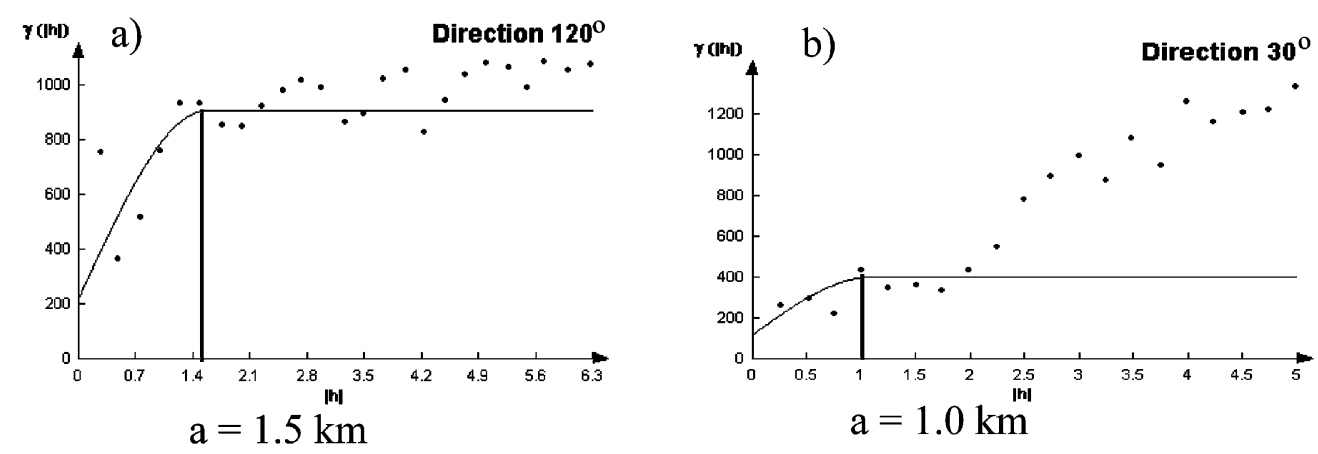

Fig. 5. Semi-variograms for fine fraction percentages in the direction of maximum continuity (a) and in the perpendicular direction (b), with the spherical model fitted.

Table 1

Examples of spatial sampling designs in coastal sediment studies

\begin{tabular}{|c|c|c|c|c|}
\hline Coastal zone & Sampling design & Number of sites/area & Aim of the study & Author \\
\hline Delaware Bay, USA & $\begin{array}{l}\text { Stratified random sampling, according } \\
\text { to EMAP }\end{array}$ & $91 / 2059 \mathrm{~km}^{2}$ & $\begin{array}{l}\text { Assessment of the ecological } \\
\text { conditions, including spatial } \\
\text { distribution of sediment } \\
\text { assessment }\end{array}$ & $\begin{array}{l}\text { Chaillou et al. (1996); } \\
\text { USEPA (1998) }\end{array}$ \\
\hline San Diego Bay, USA & $\begin{array}{l}\text { Direct sampling (for specific areas of } \\
\text { concern) and stratified random (to } \\
\text { identify spatial extent of regional } \\
\text { toxicity }\end{array}$ & $350 / 35 \mathrm{~km}^{2}$ & $\begin{array}{l}\text { Spatial pattern assessment of } \\
\text { sediment toxicity and chemical } \\
\text { concentrations }\end{array}$ & Fairey et al. (1998) \\
\hline $\begin{array}{l}\text { Eastern waters of } \\
\text { Hong Kong, China }\end{array}$ & $\begin{array}{l}\text { Systematic grid of } 5 \mathrm{~km} \text { and transects } \\
\text { running along the directions of local } \\
\text { tidal movements }\end{array}$ & $39 / 2079 \mathrm{~km}^{2}$ & $\begin{array}{l}\text { Interpolation (through Kriging) of } \\
\text { contour map for sewage pollution }\end{array}$ & Poon et al. (2000) \\
\hline $\begin{array}{l}\text { King's Docks, } \\
\text { Swansea, UK }\end{array}$ & $\begin{array}{l}\text { Stratified sampling, grid of } 405 \mathrm{~m} \text { and } \\
\text { additional sampling points located } \\
\text { randomly from each grid node with a } \\
\text { fixed range of distances between them } \\
\text { of } 135,45,15 \text { and } 5 \mathrm{~m}\end{array}$ & $101 / 0.75 \mathrm{~km}^{2}$ & $\begin{array}{l}\text { Interpolation (through Kriging) of } \\
\text { contour map and spatial scale of } \\
\text { variation for PCB contaminant } \\
\text { sediments }\end{array}$ & Reed et al. (2000) \\
\hline
\end{tabular}

essential preliminary step in ecological research. In spite of this, few efforts are being made to design sampling properly, in particular for spatial assessment of estuarine sediment quality. The aim of this study was to design a robust spatial sampling strategy for the Sado Estuary. Systematic unaligned sampling was chosen and its advantages were discussed. A final grid of $750 \times 500$ $\mathrm{m}$ was then defined using prior information on the spatial variation in the estuarine sediments. Preliminary analysis of the sampled data collected shows valid and precise interpolation results for the definition of environmentally homogeneous sediment areas in the Sado Estuary (Caeiro et al., 2003). This sampling was integrated into a GIS within a digitized Sado Estuary boundary, allowing future integration of environmental monitoring and management information. This boundary was digitized with the tidal knowledge acquired, which will also permit accurate studies of shoreline evolution and changes. These studies are of particular importance with regard to sea level changes related to natural or anthropogenic climate changes and any consequent variations in estuarine morphology.

\section{Acknowledgements}

Sandra Caeiro's work was supported by a PRODEP Program grant. The research was approved by the Portuguese Science and Technology Foundation and POCTI (Research Project POCTI/BSE 35137/99) and financed by FEDER. The sampling campaign was carried out with the support of the Sado Estuary Nature Reserve. We would also like to thank the Instituto Geográfico Português, Prof. Ana Rodrigues from University of Aveiro and Instituto Hidrográfico for making their data available. The comments of two anonymous reviewers also improved the presentation of this paper.

\section{References}

Berry, B.J.L., Baker, A.M., 1968. Geographic sampling. In: Berry, B.J.L., Marble, D.F. (Eds.), Spatial Analysis. Prentice Hall, Englewood Cliffs, NJ.

Burgess, T.M., Webster, R., 1984. Optimal sampling strategies for mapping soil types. I. Distribution of boundary spacing. Journal of Soil Science 35, 641-654. 
Caeiro, S., Goovaerts, P., Painho, M., Costa, M.H., 2003. Delineation of estuarine management areas using multivariate geostatistics: the case of Sado Estuary. Journal of Environmental Science and Technology 37(15). In press.

Caeiro, S., Painho, M., Costa, M.H., Ramos, T.B., 2002. Sado Estuary Ecosystem: a management methodology. In: Duarte, P. (Ed.), Proceedings of the International Conference on Sustainable Management of Coastal Ecosystems, Porto, Portugal, 3-5 November, 1999,

Chaillou, J.C., Weisberg, S.B., Kutz, F.W., DeMos, T.E., Mangiaracina, L., Magnien, R., Eskin, R., Maxted, J., Price, K., Summers, J.K., 1996. Assessment of the ecological condition of the Delaware and Maryland Coastal Bays. Environmental Monitoring and Assessment Program. Environmental Protection Agency. Report no. EPA/620/R-96/004.

Chrisman, N., 1997. Exploring Geographic Information Systems. John Wiley \& Sons, New York.

Clark, W.A.V., Hosking, P.L., 1986. Statistical Methods for Geographers. John Wiley \& Sons, New York.

CNIG, 1990. 1:25,000 Land use maps of the Instituto Geográfico Português.

CNIG, 1995. 1:40,000 Aerial photography of the Instituto Geográfico Português.

Cochran, W.G., 1977. Sampling Techniques, 3. John Wiley \& Sons, New York.

Fairey, R.C., Roberts, C., Jacoby, M., Lamerdin, S., Clark, R., Downing, J., Long, E., Hunt, J., Anderson, B., Newman, J., Tjeerdema, R., Stephenson, M., Wilson, C., 1998. Assessment of sediment toxicity and chemical concentration in the San Diego Bay Region, California, USA. Environmental Toxicology and Chemistry 17, $1570-1581$.

Flatman, G.T., Englund, E.J., Yfantis, A.A., 1987. Geostatistical approaches to the design of sampling regimes. In: Keith, L.H. (Ed.), Principles of Environmental Sampling. ACS Professional Reference Book. American Chemical Society, Washington.

Gomes, N., Andrade, C.F., Carapuço, M., Morgado, N., 2001. Dinâmica Costeira. In: Andrade, F. (Coord.), Estudo de Impacte Ambiental da Marina e Novo Cais dos "Ferries" do Troia Resort. Vol. II anexos.

Goovaerts, P., 1997. Geostatistics for Natural Resources Evaluation. Oxford University Press, Oxford.

Haining, R., 1990. Spatial Data Analysis in the Social and Environmental Sciences. Cambridge, Cambridge University Press.

IH, 1995. Portuguese Tidal Tables. Instituto Hidrográfico.

Jassby, A.D., Cole, B.E., Cloern, J.E., 1997. The design of sampling transects for characterizing water quality in estuaries. Estuarine, Coastal and Shelf Science 45, 285.

Kitsiou, D., Tsirtsis, G., Karydis, M., 2001. Developing an optimal sampling design. A case study in a coastal marine ecosystem. Environmental Monitoring and Assessment 71, 1-12.

Martins, F., Leitão, P., Silva, A., Neves, R., 2001. 3D modelling in the Sado estuary using a new generic vertical discretization approach. Oceanologica Acta 24, S51-S62.
Mumby, P.J., Green, E.P., Edwards, A.J., Clark, C.D., 1999. The costeffectiveness of remote sensing for tropical coastal resources assessment and management. Journal of Environmental Management 55, 157-166.

O'Regan, P.R., 1996. The use of contemporary information technologies for coastal research and management-a review. Journal of Coastal Research 12, 192-204.

Overton, W., White, D., Steven, D., 1990. Design Report for EMAP. Environmental Monitoring and Assessment Program, Environmental Protection Agency. Report no. EPA/600/3-91/053.

Painho, M., Vasconcelos, L.T., Farral, H., 1996. Tendências evolutivas territoriais em gestão ambiental: o caso do Estuário do Sado. In: Santana, F., Vasconcelos, L., Partidáro, M.R., Seixas, M.J., Sobral, M.P. (Eds.), Proceedings of 6a Conferência Nacional sobre a Qualidade do Ambiente, Lisboa, Portugal, 20-22 October, 2.

Poon, K.R., Wong, W., Lam, M.H., Yeung, H., Chiu, T.K., 2000. Geostatistical modelling of the spatial distribution of sewage pollution in coastal sediments. Water Research 34, 99-108.

Reed, J., Chappel, A., French, J.R., Oliver, M.A., 2000. A geostatistical analysis of contaminated sediment in a commercial dock in the United Kingdom. In: Proceedings of GeoEnv2000. Part II, Avignon, France, 22-24 November.

Ricketts, P.J., 1992. Current approaches in geographic information systems for coastal management. Marine Pollution Bulletin 25, 82-87.

Rodrigues, A.M., Quintino, V.M.S., 1993. Horizontal Biosedimentary Gradients across the Sado Estuary, W. Portugal. Netherlands Journal of Aquatic Ecology 27, 449-464.

Robinson, A.H., Morrison, J.L., Muehrcke, P.C., Kimmerling, A.J., Guptill, S.C., 1995. Elements of Cartography, 6. New York, John Wiley \& Sons.

Stanbury, K.B., Starr, R.M., 1999. Applications of Geographic Information Systems (GIS) to habitat assessment and marine resources management. Oceanologica Acta 22 (6), 699-703.

Thompson, S.K., 1992. Sampling. Wiley Series in Probability and Statistics, New York.

USEPA, 1998. Condition of the Mid-Atlantic Estuaries. US Environmental Protection Agency, Office of Research and Development, National Health and Environmental Effects Research Laboratory, Atlantic Ecology Division. Report no. EPA 600-R-98-147.

UKHO 1999. Portugal West Coast, Setúbal. United Kingdom Hydrographic Office.

Groenigen, J.W., Pieters, G., Stein, A., 2000. Optimizing spatial sampling for multivariate contamination in urban areas. Environmetrics $11,244$.

Groeningen, J.W., Siderius, W., Stein, A., 1999. Constrained optimisation of soil sampling for minimisation of the kriging variance. Geoderma 87, 239.

Webster, R., 1999. Sampling, estimating and understanding soil pollution. In: Gómez-Hernández, J., Soares, A., Froidevaux, R. (Eds.), GeoEnvII 98-Geostatistics for Environmental Applications. Quantitative Geology and Geostatistics. Kluwer Academic Publishers, Dordrecht. 